\title{
Experimental and Numerical Simulation of Load Deformation Behavior of a Reinforced Concrete Beam
}

\author{
Kavitha .S $\mathbf{1}^{1}$, Dr. T. Felix Kala ${ }^{2}$ \\ ${ }^{1}$ Research Scholar, Dr. M. G. R Educational Research Institute \& university, Chennai, India \\ ${ }^{2}$ Profeesor \& HOD, Dr. M. G. R Educational Research Institute \& university, Chennai, India
}

\begin{abstract}
During an earthquake, a brittle punching failure can arise in beam-column connections due to poor transfer capacity of shearing forces and unbalanced moments. To increase the shear capacity of the slab, various types of shear reinforcement can be used in the slab around the connection. The aim of the project is to study the response of beam containing with shear reinforcement when subjected to combined gravity and cyclic lateral loading. At first a calibration model was developed to simulate the tested beam-column joint using finite element analysis program MASA. This model was used to predict the load displacement behaviour. The results showed that the model predicts the load level excellently but significantly over estimates the stiffness of the joint compared to that observed by James Lee \& Ian Robertson. Since the present study is to compare the relative behaviour of beam provided with shear reinforcement, the error in the estimation of joint stiffness will not alter the comparative conclusions drawn. Thus, the developed model was validated for application to various types of beam behaviour.
\end{abstract}

Keywords: beam-column, load displacement, shear, deflection.

\section{Introduction}

When The Beam is one of the most common Structural system for buildings. It provides architectural flexibility, more clear space, less building height, easier form work, and, consequently, shorter construction time. Low floor to floor heights reduce the total building height, thus reducing lateral loads, cost of building cladding, cost of vertical mechanical and electrical lines, and air conditioning/heating costs. For vertical loads, the structural performance and design of beams are well established. A serious problem that can arise in beam column is brittle Punching Shear failure due to poor transfer capacity of shearing forces and unbalanced moments between slabs and columns. In seismic zones, a structure can be subjected to strong ground motions, and, for economical design, a structure is considered to undergo deformations in the inelastic range, therefore, in addition to strength requirement, beam-column connections must undergo these inelastic deformations without premature punching or shear failure. In other words beam column connections must have adequate ductility.

\section{Experimental Setup}

The experimental setup and reinforcement details of the beam are as shown in figures 1 and 2 respectively

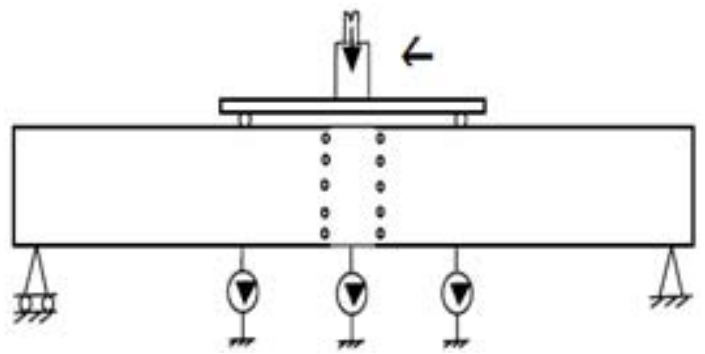

Figure 1: Experimental Setup

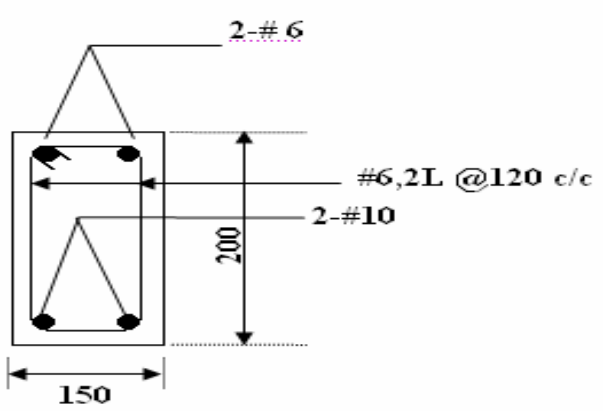

Figure 2: Cross section of Beam at mid Span

Concrete cube strength at 28 days is $27 \mathrm{MPa}$ and $\mathrm{Fe} 415$ grade steel is used for main reinforcement and Fe 250 grade steel is used for stirrups. The load is applied at middle third points. One end of the beam is hinged and the other is roller supported. The load deflection curve for the beam observed in the experiment is shown in figure 3 .

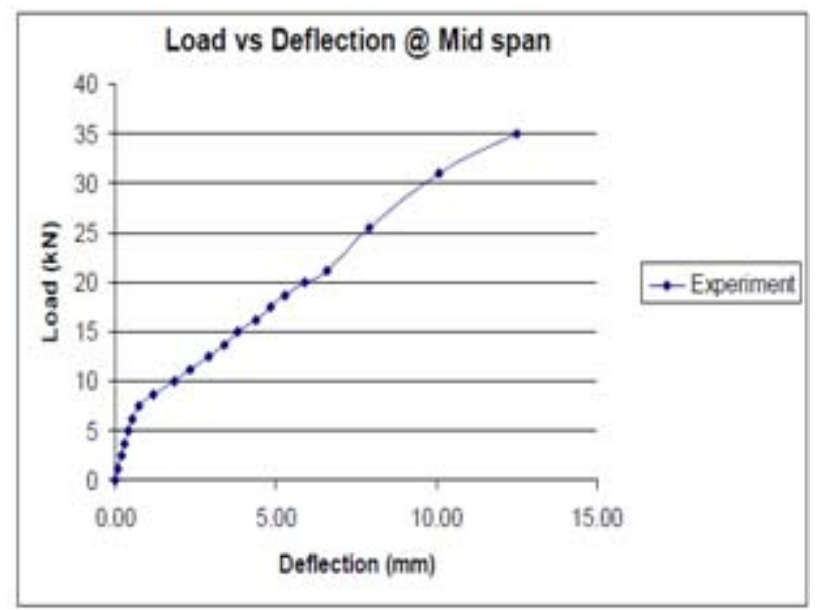

Figure 3: Load deflection curve from experimental results 


\section{Finite Element Model}

To Finite element modeling package, FEMAP is used to model the beam. Following are the steps involved in the modeling of Beam.

- Solid elements are used to model concrete and bar elements are used to model reinforcement.

- Beam is allowed to translate in loading direction alone at load rod positions and constrained in other ( $\mathrm{Y} \& \mathrm{Z}$ ) directions. Gravity load is applied on the beam in the form of point loads.

- Bottom of the beam is hinge supported and the predetermined cyclic lateral displacement routine is applied at the top of the column.

- The Bond to the reinforcement is modeled by inputting Bond-Slip curve in the analysis.

- The finite element model developed in FEMAP is transferred to MASA for the analysis.

The finite element mesh for the beam is as shown figure 4 . One end of the beam is hinged and the other is roller supported. 3D Solid elements are used to model concrete and 1D Bar elements are used to model reinforcing bars. The figures 5 and 6 show finite element mesh for the beam model The beam model is then transferred to MASA for analysis and material properties and loading data are defined. The resulting load deflection curve from the analysis is as shown in figure 7 .

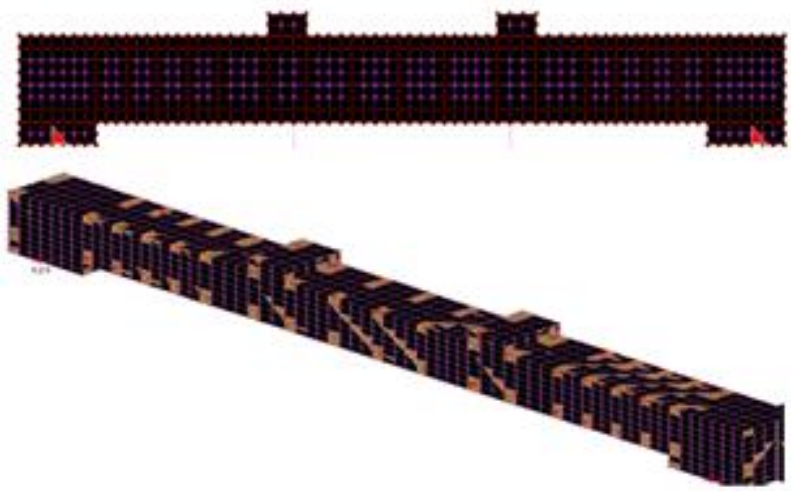

Figure 4: Geometry of the model

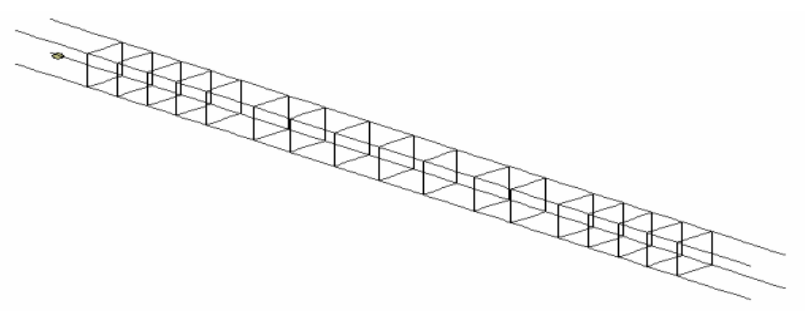

Figure 5: Reinforcement configuration

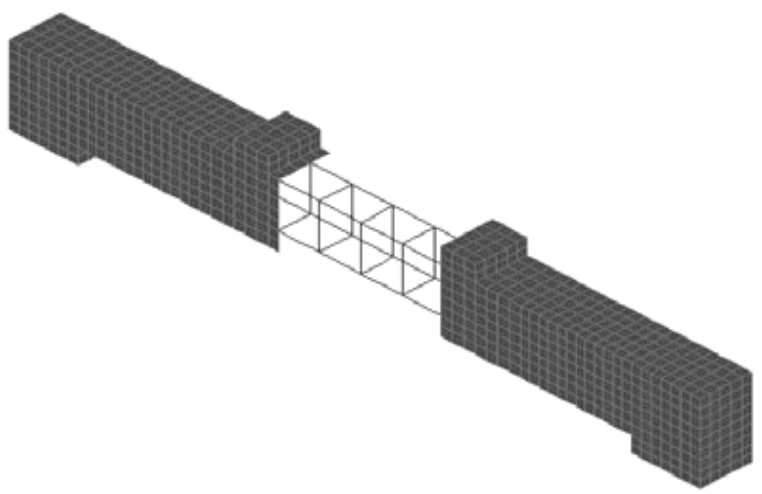

Figure 6: Finite element mesh (selected concrete elements removed to illustrate internal reinforcement)

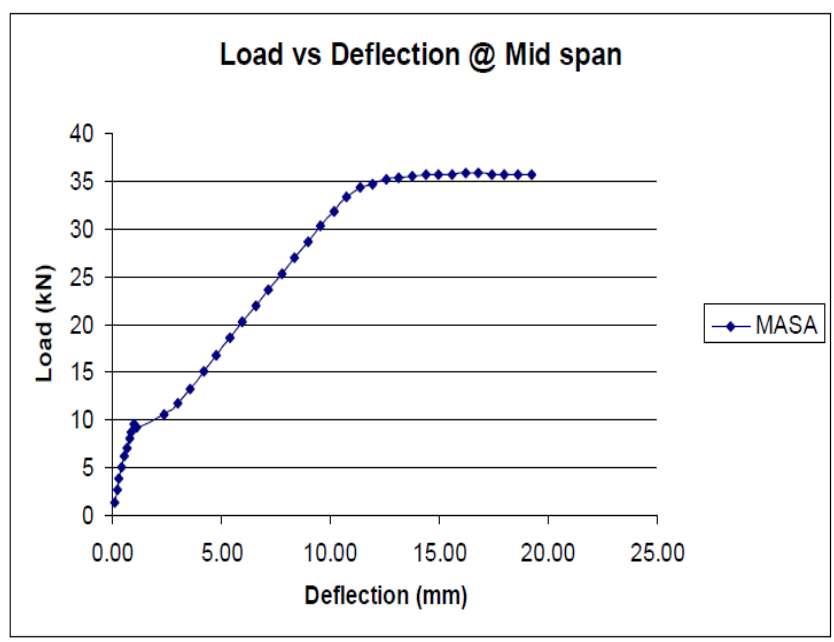

Figure 7: Load deflection curve

\section{Comparison of Experimental and Numerical Results}

The load deflection response for the beam, from the experiment, is plotted with the finite element results as shown below in fig 8 . The numerical model predicts an ultimate load of $35.75 \mathrm{kN}$ and captures well the nonlinear load deflection response of the beams up to failure. The ultimate load reached in the test was $35.00 \mathrm{kN}$. The deformed shape and crack pattern observed in the beam model are shown in figures 9 and 10 respectively.

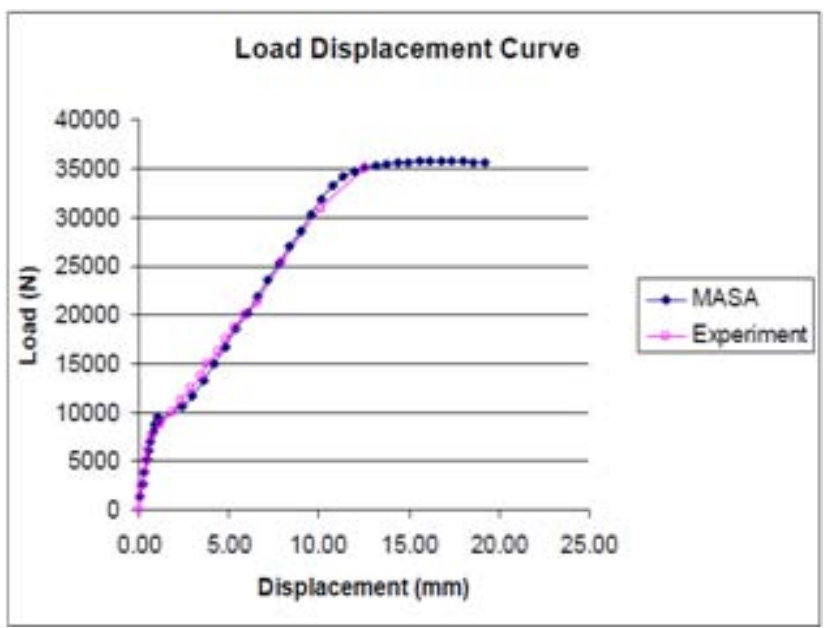

Figure 8: Comparison of load deflection curves 


\section{International Journal of Science and Research (IJSR) \\ ISSN (Online): 2319-7064}

Index Copernicus Value (2013): 6.14 | Impact Factor (2014): 5.611

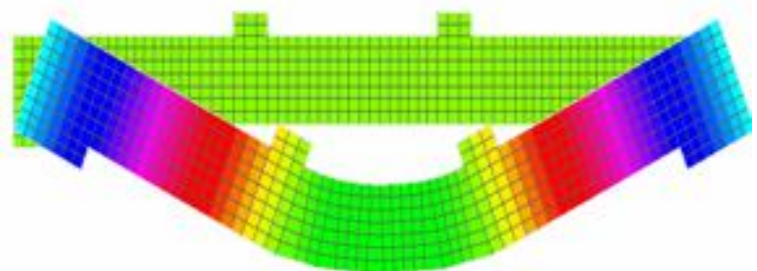

Figure 9: Deformed Shape

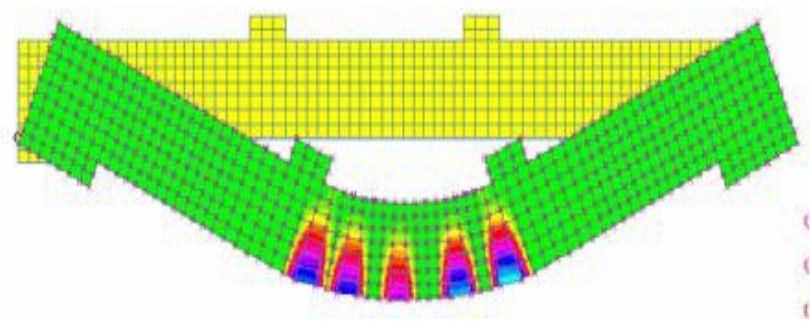

Figure 10: Crack pattern

The figure 11 shows the stresses in the reinforcing bars at peak load. The figures 12 and 13 show stresses and stains respectively in the reinforcing bars of mid span at Peak load.

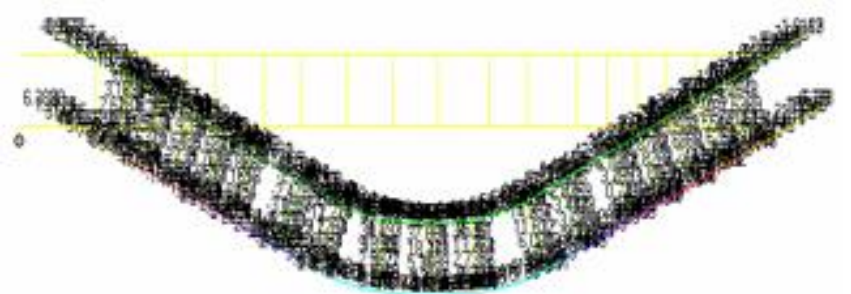

Figure 11: Stresses in Reinforcing Bars

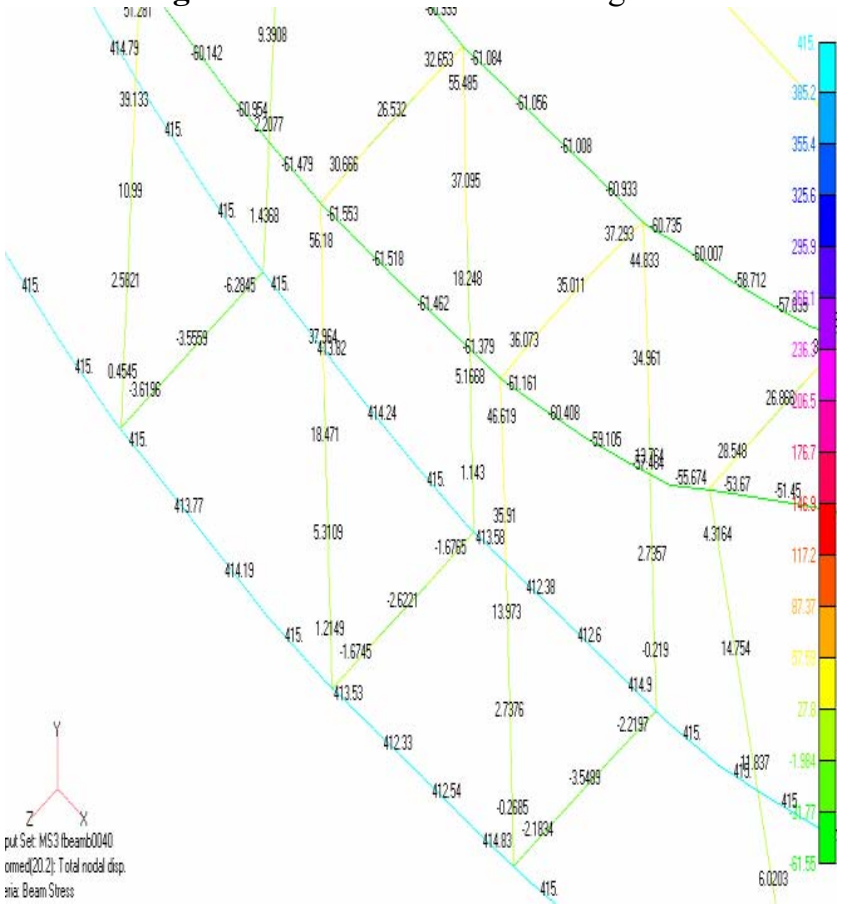

Figure 12: Stress in Reinforcing Bars of mid span at Peak load

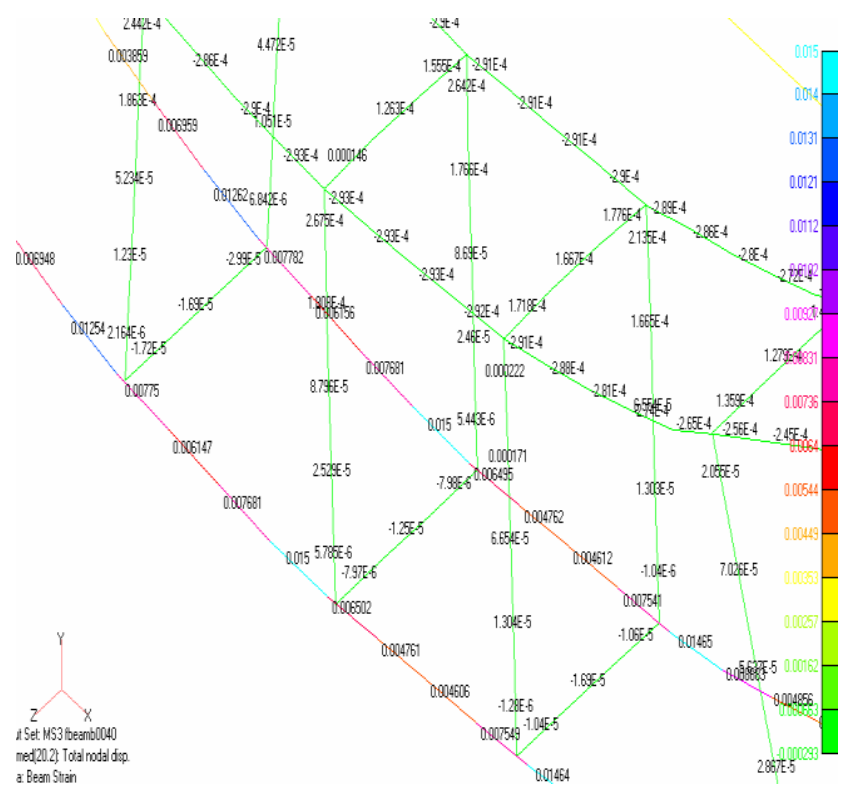

Figure 13: Strains in Reinforcing Bars of mid span at Peak load

\section{Conclusions}

From the above model, the finite element modeling and analysis softwares FEMAP and MASA reveal the strengths and weaknesses of the model. The model predicts the load level excellently but significantly over estimates the stiffness of the joint.

\section{References}

[1] A. A. ACI Committee 318 (2005), "Building Code Requirement for Reinforced Concrete and Commentary,".

[2] Austin D. Pan., and Jack P. Moehle. (1992), "An Experimental Study of Slab-Column Connections," ACI Structural Journal, Vol. 89, No.6, November-December 1992, pp.626-638.

[3] Carl Erik Broms. (2007), "Flat Plates in Seismic Areas, Comparison of Shear Reinforcement Systems," ACI Structural Journal, Vol. 104, No.6, November-December 2007, pp. 712721.

[4] Carl Erik Broms. (2007), "Ductility of Flat Plates, Comparison of Shear Reinforcement Systems," ACI Structural Journal, Vol. 104, No.6, November-December 2007, pp. 703-711.

[5] Fanning P. (2001), "Nonlinear Models of Reinforced and Post-tensioned Concrete Beams," Electronic Journal of Structural Engineering.

[6] Fee Kiong Lim., and B. Vijaya Rangan. (1995), "Studies on Concrete Slabs with Stud Shear Reinforcement in Vicinity of Edge and Corner Columns," ACI Structural Journal, Vol. 92, No.5, September-October 1995, pp. 515-525.

[7] Hong-gun Park., Kyung-soo Ahn., Kyoung-kyu Choi., and Lan Chung., (2007) "Lattice Shear Reinforcement for Slab-Column Connections," ACI Structural Journal,Vol. 104, No.3, May-June 2007, pp. 294-303.71

[8] Ian N. Robertson., Tadashi Kawai., James Lee., and Brian Enomoto. (2002), "Cyclic Testing of Slab-Column Connections with Shear Reinforcement," ACI Structural 


\section{International Journal of Science and Research (IJSR) \\ ISSN (Online): 2319-7064}

Index Copernicus Value (2013): 6.14 | Impact Factor (2014): 5.611

Journal, Vol. 99, No.5, September-October 2002, pp. 605-613.

[9] Ian N. Robertson. (1997), "Analysis of Flat Slab Structures Subjected to Combined Lateral and Gravity Loads," ACI Structural Journal, Vol. 94, No.6, November-December 1997, pp. 723-729.

[10]IS 456 (2000), "Indian Standard Code of practice for plain and reinforced concrete,"Bureau of Indian Standards, New Delhi.

[11]IS 1893 (part 1): (2002), "Indian standard Code of practice for Earthquake Resistant design of structures," Bureau of Indian Standards, New Delhi.

[12] IS 13920 (1993), "Indian Standard Code of practice for ductile detailing of Reinforced Concrete structures subjected to seismic forces," Bureau of Indian Standards, New Delhi.

[13] John F. Brotchie. (1980), "Some Australian Research on Flat Plate Structures," ACI Journal, January-February 1980, pp. 3-11.

[14] Ožbolt J. (2005), "MASA 3 Manual," Institut für Werkstoffe im Bauwesen Universität Stuttgart 70550 Stuttgart, Germany.

[15] Sami Megally., and Amin Ghali. (1994), "Design Considerations for Slab-Column Connections in Seismic Zones," ACI Structural Journal, Vol. 91, No.3, MayJune 1994,pp. 303-314.

\section{Author Profile}

Kavitha. S received the B.Tech and M.Tech degrees in civil Engineering from Dr.M.G.R Educational \& Research Institute university, Chennai ,India.now she is working as assistant professor in ACS College of engineering,Bangalore and doing her Ph.D. 